\title{
Outcomes of Retinectomy in Rhegmatogenous Retinal Detachment with Proliferative Vitreoretinopathy
}

\author{
Saliha Naz, Syed Fawad Rizvi, Faisal Murtaza and Basheeran Shehzadi
}

\begin{abstract}
Objective: To evaluate the anatomical and functional outcomes of retinectomy in the management of primary rhegmatogenous retinal detachments with inferior retinal breaks and advanced proliferative vitreoretinopathy (PVR C).

Study Design: Quasi-experimental study.

Place and Duration of Study: LRBT, Free Base Eye Hospital, Karachi, from July 2015 to June 2017.

Methodology: Forty eyes of 40 patients with primary inferior retinal breaks macula off detachments and advanced proliferative vitreoretinopathy (grade C) in which retinectomy was performed were included. Primary outcome measured was anatomic success, defined as complete retinal reattachment between neurosensory retina and retinal pigment epithelium at six months follow-up. Secondary outcomes included changes in best corrected visual acuity and postoperative complications. The follow-up period was up to six months after the last surgery. Association was determined between the retinectomy extension and the best corrected visual acuity postoperatively.

Results: Retina was reattached after single operation in 29 eyes (72.5\%), after the second operation in eight eyes $(20 \%)$, and after the third operation in two eyes (5\%). Final retinal reattachment was achieved in 39 out of 40 eyes $(97.5 \%)$. The preoperative visual acuity was counting fingers CF in eight eyes (20\%), hand motion HM in 28 eyes (70\%), and light perception PL in four eyes (10\%). The postoperative visual acuity improved in 27 eyes $(67.5 \%)$, remained stable in 11 eyes $(27.5 \%)$, and worsened in 2 eyes $(5 \%)$. There was no statistically significant association between the retinectomy extension and maximum postoperative best corrected visual acuity $(p=0.098)$. The significant postoperative complications were retinal redetachment and hypotony.

Conclusion: Retinectomies are effective in managing primary rhegmatogenous retinal detachment with severe PVR (PVR C), and Increase the final retinal reattachment rate.
\end{abstract}

Key Words: PVR C, Retinectomy, Rhegmatogenous retinal detachment.

\section{INTRODUCTION}

Rhegmatogenous retinal detachment (RRD) complicated by inferior retinal breaks and proliferative vitreoretinopathy (PVR) remains a challenging situation for vitreoretinal surgery. ${ }^{1}$ High grade PVR (PVR C) is the most common cause of recurrent retinal detachment after surgery. ${ }^{2}$ The main problem is that any classic endotamponade agent, either gas or silicone oil, does not completely cover the lower quadrant; and the highgrade PVR leads to recurrence of the retinal detachment. ${ }^{2}$ Some surgeons prefer scleral buckling (SB) combined with vitrectomy to increase the endo tamponading effect. But the use of the scleral buckle has its own complications, such as choroidal hemorrhage, prolonged operation time, refractive change, diplopia, possible decreased retinal blood flow and risk of anterior segment ischemia. ${ }^{3}$

Machemer introduced the term retinotomy and retinectomy. These procedures were reserved for complicated

Department of Ophthalmology, LRBT Free Base Eye Hospital, Karachi, Pakistan

Correspondence: Dr. Saliha Naz, LRBT Free Base Eye Hospital,

Korangi 2 1⁄2, Karachi, Pakistan

E-mail:drsalihanaz@live.com

Received: March 09, 2018; Accepted: July 12, 2018
RDs as a secondary procedure to achieve retinal flatening. ${ }^{4}$ Retinectomies are indicated when the retina is shortened by a long standing detachment with intrinsic retinal shortening, proliferation and fibrous contraction. 5 This shortening of the retina prevents the approximation of the neurosensory retina with the retinal pigment epithelium during or after surgery.

Nowadays, there is a generalized shift towards the use of primary vitrectomy by majority of surgeons rather than scleral buckling as the first choice and retinectomy as a primary procedure for advanced PVR. ${ }^{6}$ In the past, retinectomy was used to deal high risk cases with eminent surgical failure like complicated tractional retinal detachments, endophthalmitis, acute retinal necrosis and post-traumatic cases.

The aim of this study was to evaluate the role of retinectomy as a first line procedure for the treatment of primary rhegmatogenous retinal detachments (RRDs) with advanced PVR (grade C) and for evaluation of changes in visual acuity and postoperative complications.

\section{METHODOLOGY}

Forty eyes of 40 patients with primary RRD with inferior retinal breaks and PVR $\geq \mathrm{C} 3$ (according to the classification of Retina Society) were enrolled in the study after approval of the Hospital Ethical Committee and patient's written informed consent. 
Inclusion criteria were age over 18 years, primary RRD, one or more inferior breaks (horseshoe tear or round hole between 4 o'clock and 8 o'clock), and PVR $\geq \mathrm{C} 3$. Exclusion criteria were previously operated eyes by buckle or vitrectomy, retinal dialysis, giant retinal tears, macular holes, proliferative diabetic retinopathy, trauma, retinal vascular diseases, and choroidal detachment.

All patients had clinical examinations by slit-lamp biomicroscopy and indirect ophthalmoscopy. Preoperative data collected on each patient included age, gender, visual acuity, intraocular pressure (IOP), type and distribution of all retinal breaks, area of detachment and grade of PVR, and no signs of previous retinal surgery.

The surgical technique included $360^{\circ}$ peritomy, standard 20 guage pars plana vitrectomy, which was done by an experienced vitreoretinal surgeon under general or retrobulbar anesthesia using Constellation Vision System (Alcon) and LUMERA-700 microscope with SDI III BIOM. After meticulous vitreous removal, subretinal fluid was drained via accessible retinal break with injection of a perfluorocarbon liquid. The decision of retinectomy extension was taken by the surgeon on table when residual traction could not be released from $180^{\circ}$ to $360^{\circ}$ as required. A $360^{\circ}$ endolaser photocoagulation was carried out and direct PFCL silicon oil exchange was done. To tamponade, the retina postoperatively 5000 centistokes silicone oil was used in every case. All patients were postured face-down (50 minutes of every hour with 10 minutes rest) for two weeks after surgery.

The anatomic success, visual acuity, and complications were recorded and analyzed. The anatomical success was defined as retinal reattachment up to 6 months postoperatively. Eyes with redetachments after first surgery (because of recurrent PVR) underwent another procedure for removal of silicon oil, epiretinal and subretinal membranes and extension of retinectomy. This was followed by endolaser photocoagulation and silicon oil refill.

Statistical analysis was done using SPSS version 13.0. Normality of data was checked by Kolmogorov-Smirnov test. Median with interquartile value (due to nonparametric data) for quantitative variable (age), mean (SD) for following normal distribution assumptions and frequencies along with percentages for qualitative variables were used to describe the data. Chi-square test to check association between the extension of retinectomy and postoperative visual acuity was applied. A $p$-value of $\leq 0.05$ was considered statistically significant.

\section{RESULTS}

Forty eyes of 40 patients were included in this study, 29 $(72.5 \%)$ males and $11(27.5 \%)$ females, as shown in Figure 1, with a median age (IQR) of 51.5 (21) years (between 18 and 65 years) and a minimum follow-up time of six months, ranging from six to 24 months. The preoperative BCVA was counting fingers (CF) in 8 patients $(20 \%)$, hand motions (HM) in 28 patients $(70 \%)$, and light perception (PL) in 4 patients $(10 \%)$, as shown in Figure 2. Before the operation, two eyes $(5 \%)$ were aphakic, 18 eyes (45\%) were pseudophakic, and 20 eyes $(50 \%)$ were phakic. The mean preoperative IOP was $11.5 \pm 3.7 \mathrm{mmHg}$ ranging from 5 to $21 \mathrm{mmHg}$. The PVR was classified as grade C3-C6 in 24 eyes $(60 \%)$, and $\mathrm{C} 7-\mathrm{C} 12$ in 12 eyes (30\%), (Figure 3). Four of the 40 eyes $(10 \%)$ had anterior PVR. All eyes were macula-off detachments.

The complete postoperative retinal flattening or reattachment after a single operation was achieved in 29 of 40 eyes $(72.5 \%)$, after two operations in 8 eyes $(20 \%)$, and after the third operation in 2 eyes $(5 \%)$. One eye $(2.5 \%)$ did not achieve retinal reattachment even after the third surgery. At the end of follow-up, the retina was

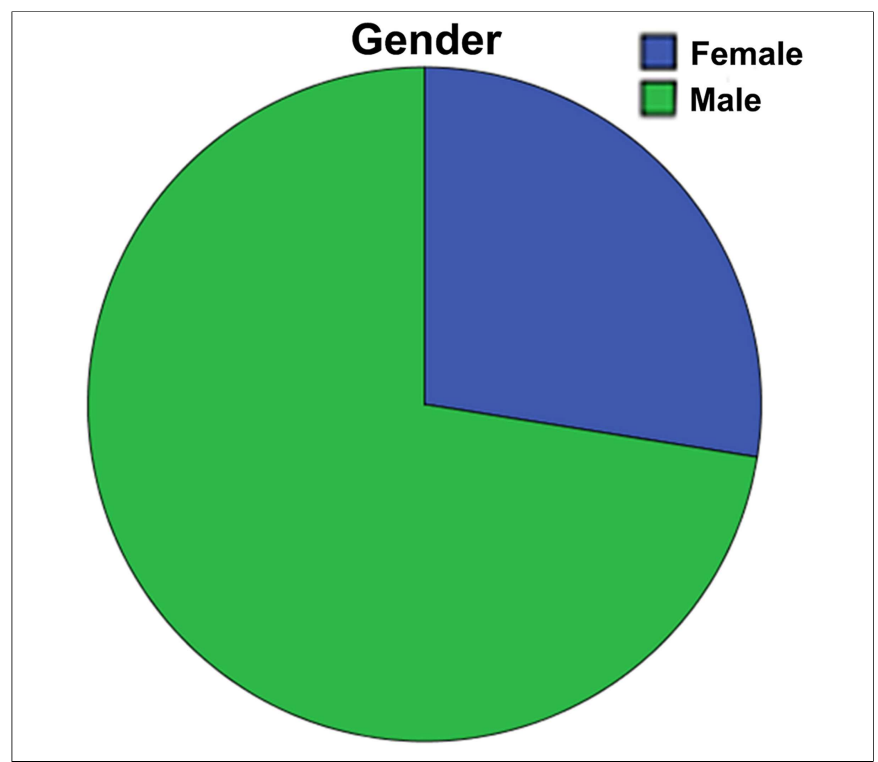

Figure 1: Gender distribution

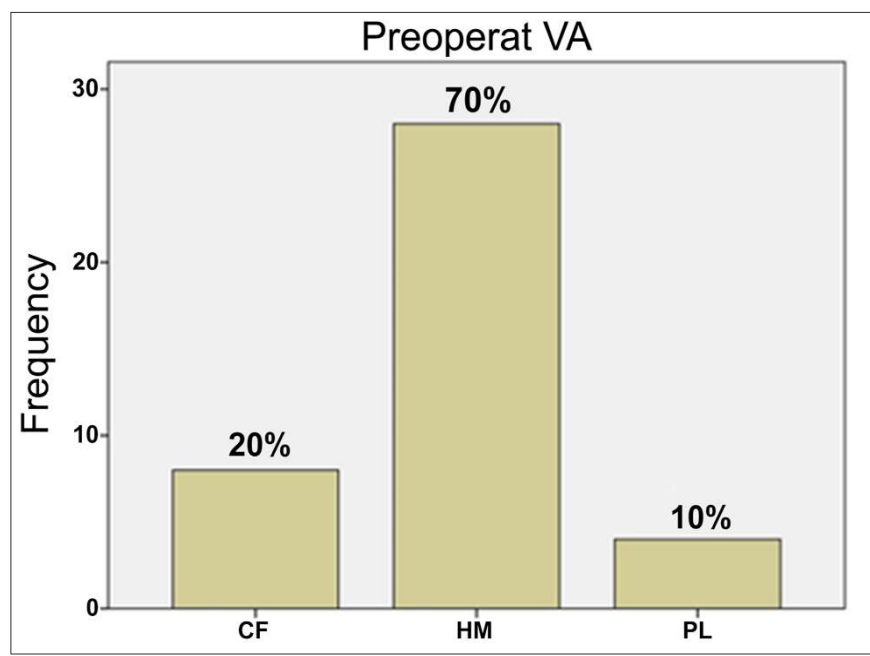

Figure 2: Preoperative BCVA in CF, HM and PL. 


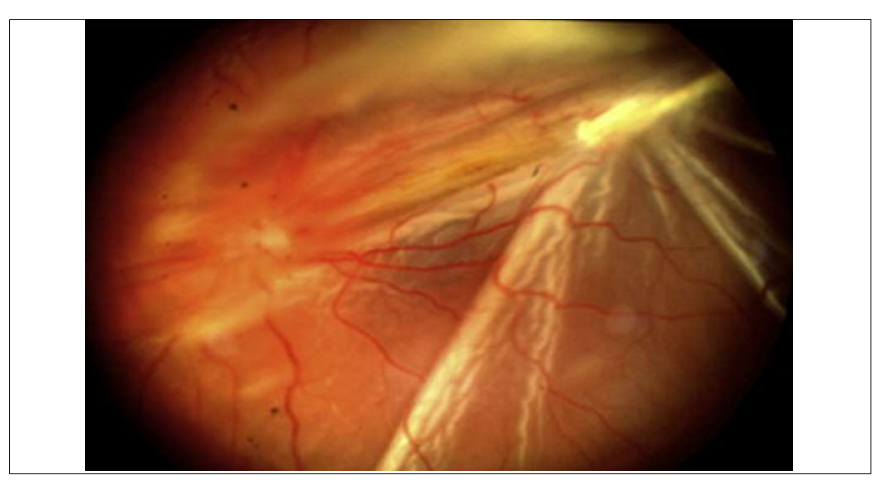

Figure 3: Rhegmatogenous retinal detachment with PVR C.

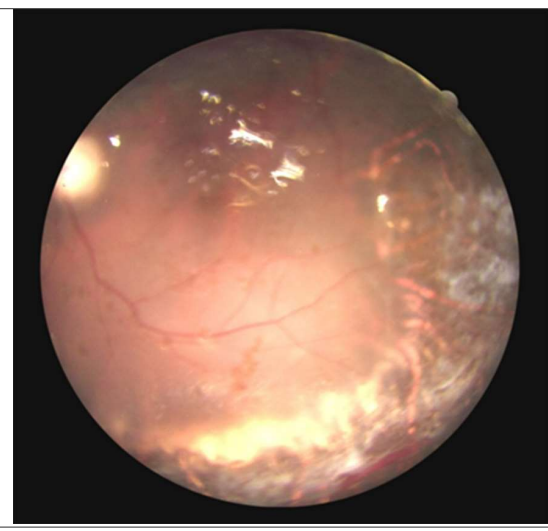

Figure 4: Postoperative attached retina with silicon oil.

Table I: Anatomical outcome after pars plana vitrectomy with retinectomy.

\begin{tabular}{l|c|c|c}
\hline \multirow{2}{*}{$\begin{array}{l}\text { Total No. of surgeries } \\
\text { *final retina status }\end{array}$} & \multicolumn{2}{|c|}{ Final retina status } & \multirow{2}{*}{ Total } \\
\cline { 2 - 3 } & Attached & Detached & \\
\hline 1.00 Frequency (\% of total) & $29(72.5 \%)$ & $0(0.0 \%)$ & $29(72.5 \%)$ \\
2.00 Frequency (\% of total) & $8(20 \%)$ & $0(0 \%)$ & $8(20 \%)$ \\
3.00 Frequency (\% of total) & $2(5 \%)$ & $1(2.5 \%)$ & $3(7.5 \%)$ \\
\hline Total & $39(97.5 \%)$ & $1(2.5 \%)$ & $40(100 \%)$ \\
Final anatomical success (\% of total) & & & \\
\hline
\end{tabular}

successfully reattached in 39 eyes (97.5\%), (Figure 4). The final anatomical success rate was $97.5 \%$, as shown in Table I.

At six months postoperatively, $27(67.5 \%)$ eyes improved their BCVA, stability in $11(27.5 \%)$, while worsening of vision was observed in $2(5 \%)$. No patient achieved a postoperative BCVA better than $6 / 36$. Regarding the extension of the retinectomy, $20(50 \%)$ eyes underwent a retinectomy up to $180^{\circ}, 10(25 \%)$ from $181^{\circ}$ to $270^{\circ}$ and the remaining $10(25 \%)$ from $271^{\circ}$ to $360^{\circ}$ to achieve the flattening of the retina. There was no significant relationship between the retinectomy extension and maximum postoperative best corrected visual acuity $(p=0.098)$, as shown in Table II.

Two eyes (5\%) had an intraocular pressure $<5 \mathrm{mmHg}$ at six months of follow-up. Not even a single eye developed phthisis bulbi up to six months of follow-up.

\section{DISCUSSION}

Proliferative vitreoretinopathy is the main cause of failure in retinal detachment surgeries. 7,8 The complete removal of preretinal membranes and traction of the retina in severe PVR (PVR grade C) is not possible without relaxing retinectomies. ${ }^{9}$ This study shows the effect of retinectomy in primary RRD surgery with advanced PVR C. The rate of anatomical success in this study after the first retinectomy was $72.5 \%$, and the final success rate after the second and third retinectomies was $97.5 \%$, which is comparable with previous national and global studies carried out to evaluate the result of retinectomy with a success rate between $52 \%$ to $98.8 \% .5,7,10-13$ This diversity in the results are attributed to the differences in the severity of the pathology, the degrees of retinectomy extension, the inclusion and exclusion criteria and surgical approaches.

Table II: Outcomes of retinectomy in rhegmatogenous retinal detachment with proliferative vitreoretinopathy.

\begin{tabular}{|c|c|c|c|c|c|c|c|c|}
\hline \multicolumn{2}{|c|}{ Postoperative BCVA } & \multicolumn{5}{|c|}{ Retinectomy extension } & \multirow{3}{*}{\begin{tabular}{|l|} 
Total \\
2 \\
$5.0 \%$ \\
\end{tabular}} & \multirow{4}{*}{$\begin{array}{c}\mathrm{p} \text {-value } \\
\text { Chisquare } \\
\text { alue }=23.575 \\
\mathrm{df}=28 \\
\mathrm{P}=0.098\end{array}$} \\
\hline & & \multirow{2}{*}{$\begin{array}{l}180.00 \\
1 \\
2.5 \% \\
\end{array}$} & \multirow{2}{*}{$\begin{array}{l}200.00 \\
0 \\
0.0 \%\end{array}$} & \multirow{2}{*}{$\begin{array}{l}270.00 \\
0 \\
0.0 \% \\
\end{array}$} & \multirow{2}{*}{$\begin{array}{l}300.00 \\
1 \\
2.5 \% \\
\end{array}$} & \multirow{2}{*}{$\begin{array}{l}360.00 \\
0 \\
0.0 \%\end{array}$} & & \\
\hline $6 / 36$ & $\begin{array}{l}\text { Count } \\
\% \text { of total }\end{array}$ & & & & & & & \\
\hline $6 / 60$ & $\begin{array}{l}\text { Count } \\
\% \text { of Total }\end{array}$ & $\begin{array}{l}2 \\
5.0 \%\end{array}$ & $\begin{array}{l}0 \\
0.0 \%\end{array}$ & $\begin{array}{l}0 \\
0.0 \%\end{array}$ & $\begin{array}{l}0 \\
0.0 \%\end{array}$ & $\begin{array}{l}0 \\
0.0 \%\end{array}$ & $\begin{array}{l}2 \\
5.0 \%\end{array}$ & \\
\hline $4 / 60$ & $\begin{array}{l}\text { Count } \\
\% \text { of Total }\end{array}$ & $\begin{array}{l}1 \\
2.5 \%\end{array}$ & $\begin{array}{l}0 \\
0.0 \%\end{array}$ & $\begin{array}{l}0 \\
0.0 \%\end{array}$ & $\begin{array}{l}0 \\
0.0 \%\end{array}$ & $\begin{array}{l}0 \\
0.0 \%\end{array}$ & $\begin{array}{l}1 \\
2.5 \%\end{array}$ & \\
\hline $2 / 60$ & $\begin{array}{l}\text { Count } \\
\% \text { of Total }\end{array}$ & $\begin{array}{l}1 \\
2.5 \% \\
\end{array}$ & $\begin{array}{l}0 \\
0.0 \%\end{array}$ & $\begin{array}{l}0 \\
0.0 \%\end{array}$ & $\begin{array}{l}0 \\
0.0 \%\end{array}$ & $\begin{array}{l}0 \\
0.0 \%\end{array}$ & $\begin{array}{l}1 \\
2.5 \% \\
\end{array}$ & \\
\hline $1 / 60$ & $\begin{array}{l}\text { Count } \\
\% \text { of Total }\end{array}$ & $\begin{array}{c}4 \\
10.0 \%\end{array}$ & $\begin{array}{l}0 \\
0.0 \%\end{array}$ & $\begin{array}{l}0 \\
0.0 \%\end{array}$ & $\begin{array}{l}0 \\
0.0 \%\end{array}$ & $\begin{array}{l}1 \\
2.5 \% \\
\end{array}$ & $\begin{array}{c}5 \\
12.5 \%\end{array}$ & \\
\hline $\mathrm{CF}$ & $\begin{array}{l}\text { Count } \\
\% \text { of Total }\end{array}$ & $\begin{array}{c}4 \\
10.0 \%\end{array}$ & $\begin{array}{l}3 \\
7.5 \%\end{array}$ & $\begin{array}{l}2 \\
5.0 \%\end{array}$ & $\begin{array}{l}3 \\
7.5 \% \\
\end{array}$ & $\begin{array}{l}1 \\
2.5 \% \\
\end{array}$ & $\begin{array}{l}13 \\
32.5 \%\end{array}$ & \\
\hline $\mathrm{HM}$ & $\begin{array}{l}\text { Count } \\
\% \text { of Total }\end{array}$ & $\begin{array}{c}7 \\
17.5 \%\end{array}$ & $\begin{array}{l}0 \\
0.0 \%\end{array}$ & $\begin{array}{c}4 \\
10.0 \%\end{array}$ & $\begin{array}{l}2 \\
5.0 \% \\
\end{array}$ & $\begin{array}{l}1 \\
2.5 \% \\
\end{array}$ & $\begin{array}{l}14 \\
35.0 \%\end{array}$ & \\
\hline $\mathrm{PL}$ & $\begin{array}{l}\text { Count } \\
\% \text { of Total }\end{array}$ & $\begin{array}{l}0 \\
0.0 \%\end{array}$ & $\begin{array}{l}0 \\
0.0 \%\end{array}$ & $\begin{array}{l}1 \\
2.5 \% \\
\end{array}$ & $\begin{array}{l}0 \\
0.0 \%\end{array}$ & $\begin{array}{l}1 \\
2.5 \% \\
\end{array}$ & $\begin{array}{l}2 \\
5.0 \% \\
\end{array}$ & \\
\hline$\overline{\text { Total }}$ & $\begin{array}{l}\text { Count } \\
\% \text { of Total }\end{array}$ & $\begin{array}{l}20 \\
50.0 \%\end{array}$ & $\begin{array}{l}3 \\
7.5 \%\end{array}$ & $\begin{array}{c}7 \\
17.5 \%\end{array}$ & $\begin{array}{c}6 \\
15.0 \%\end{array}$ & $\begin{array}{c}4 \\
10.0 \%\end{array}$ & $\begin{array}{c}40 \\
100.0 \%\end{array}$ & \\
\hline
\end{tabular}


The rate of reoperation after the first procedure in this study was $27.5 \%$. Other national and global studies showed a recurrent detachment rate of 17 to $48 \%$ after $180^{\circ}-360^{\circ}$ retinectomies. $5,7,14$ The retinectomy causes exposure of retinal pigment epithelium, with subsequent migration of pigment and inflammatory cells on the retinal surface, enhancing postoperative PVR. ${ }^{15-17}$

The improvement in the best corrected visual acuity (BCVA) in this study is comparable to the study performed by Tranos et al., in which the BCVA improved by $72 \%$, remained the same by $22 \%$, and worsened in $6 \%,{ }^{6}$ while Grigoropoulas et al. in their series reported a less favourable outcome with improvement in VA in 138 eyes $(45 \%)$, stabilisation in 73 eyes $(24 \%)$, and deterioration in $89(29 \%) .12$

This can be explained on the basis that Grigoropoulas in his study included not only PVR secondary to RRD, but also post-traumatic and tractional RRDs, vasoproliferative vasculitides, acute retinal necrosis and endophthalmitis.

Tseng et al. reported that lens removal is not mandatory in all cases of PVR 10 in distinction to the technique of Quiram et al., that dissection of the anterior base routinely includes the removal of the crystalline lens or intraocular lens. ${ }^{11}$ In this study, only two cases required lensectomy during surgery for clear vision and complete relief of traction.

Han et al. and Grigoropoulos et al. considered the size of the retinectomy as a risk factor against the recovery of visual function, 12,18 while Khaled AG Shalaby found no statistically significant relationship between the size of the retinectomy and postoperative visual acuity. ${ }^{9}$ This study also showed no statistically significant relationship between the anatomical and functional results and the size of the retinectomy. Eyes achieving the best postoperative BCVA were those that had a better initial preoperative visual acuity.

The cause of recurrent redetachment is the reproliferation of membranes on the posterior border of the retinectomy and formation of new breaks.18,19 Tseng et al. reported that redetachment depends on the extent of retinotomy and it has been reported that it occurs in $18 \%$ to $100 \%$ of cases. ${ }^{10}$ Shalaby reported a recurrent RRD rate of $18.4 \%$ due to reproliferation of the epiretinal membranes at the posterior border of the retinotomy. ${ }^{9}$ This study showed a redetachment rate of $27.5 \%$ after the first surgery, which is worse than the results reported by Shalaby.

After a large retinectomy, postoperative ocular hypotony is frequently encountered and previous studies showed a rate of $15-40 \%$ in the eyes with $360^{\circ}$ retinectomy. ${ }^{20-24}$ This study showed a rate of only $5 \%$ and no patient developed phthisis bulbi. The decreased rate of ocular hypotony could be attributable to the use of $5000 \mathrm{cs}$ silicone oil as a postoperative tamponade in all cases and its delayed removal.
The smaller sample size, the shorter follow-up period, and the lack of comparative group in which vitrectomy combined with the scleral buckling performed for the treatment of advanced PVR, are the main limitations of this study.

\section{CONCLUSION}

Proliferative vitreoretinopathy is a main cause of surgical failure of RRD, and occasionally repeated procedures are required to achieve retinal flattening. Retinectomy can lead to a higher anatomical success rate in advanced PVR cases by relaxing the stiff retina and can result in improved outcomes in terms of final visual acuity or ocular hypotony.

\section{REFERENCES}

1. Tseng W, Cortez RT, Ramirez G, Stinnett S, Jaffe GJ. Prevalence and risk factors for proliferative vitreoretinopathy in eyes with rhegmatogenous retinal detachment but no previous vitreoretinal surgery. Am J Ophthalmol 2004; 137:1105-15.

2. Mancino R, Aiello F, Ciuffoletti E, Di Carlo E, Cerulli A, Nucci C. Inferior retinotomy and silicone oil tamponade for recurrent inferior retinal detachment and grade C PVR in eyes previously treated with pars plana vitrectomy or scleral buckle. BMC Ophthalmol 2015; 15:173

3. Tanner V, Minihan M, Williamson TH. Management of inferior retinal breaks during pars plana vitrectomy for retinal detachment. Br J Ophthalmol 2001; 85:480-2.

4. Machemer R. Retinotomy. Am J Ophthalmol 1981; 92:768-74.

5. Mukhtar A. Anatomical success in patients after retinectomy for complex retinal detachment. Pak Armed Forces Med J 2015; 65:231-4.

6. Tranos P, Vakalis A, Asteriadis S, Lokovitis E, Georgalas I, Stavrakas P. Anatomic and functional outcomes of retinectomy for the management of complicated retinal detachment with proliferative vitreoretinopathy. Therapeut Clin Risk Manage 2015; 11:1515-21.

7. Adhi MI, Siyal N, Aziz S. Anatomical and functional outcomes of retinectomies in retinal detachment complicated by proliferative vitreoretinopathy. Saudi J Ophthalmol 2017; 31:216-23.

8. Wiedemann P, Yandiev Y, Hui YN, Wang Y. Pathogenesis of proliferative vitreoretinopathy. In: Ryan S.J, ed. Retina. ed. $5^{\text {th }}$ Mosby, Inc; St Louis, Missouri; 2013. p.1640-6.

9. Shalaby KA. Relaxing retinotomies and retinectomies in the management of retinal detachment with severe proliferative vitreoretinopathy (PVR). Clin Ophthalmol 2010; 4:1107-14.

10. Tseng JJ, Barlie GR, Schiff WM, Akar Y, Vidne-Hay O, Chang S. Relaxing retinotomy on surgical outcomes in proliferative vitreoretinopathy. Am J Ophthalmol 2005; 140:628-36

11. Quiram PA, Gonzales CR, Hu W, Gupta A, Yoshizumi MO, Kreiger AE. Outcomes of vitrectomy with inferior retinectomy in patients with recurrent rhegmatogenous retinal detachments and proliferative vitreoretinopathy. Ophthalmology 2006; 113: 2041-7.

12. Grigoropoulos VG, Benson S, Bunce C, Charteris DG. Functional outcome and prognostic factors in 304 eyes managed by retinectomy. Graefes Arch Clin Exp Ophthalmol $2007 ; 245: 641-9$. 
13. Banaee T, Hosseini SM, Eslampoor A, Abrishami M, Moosavi M. Peripheral 360 degrees retinectomy in complex retinal detachment. Retina 2009; 29:811-8.

14. Mendes TS, Gomes AMV, Rocha BS, Passos Junior HV, Abujamra $S$. Evaluation of retinectomy in the treatment of severe proliferative vitreoretinopathy. Int $J$ Retina Vitreous 2015; $1: 17$.

15. Charteris DG, Sethi CS, Lewis GP, Fisher SK. Proliferative vitreoretinopathy-developments in adjunctive treatment and retinal pathology. Eye 2002; 16:369-74.

16. Furino C, Micelli FT, Boscia F, Cardascia N, Recchimurzo N, Sborgia C. Plana vitrectomy for proliferative vitreoretinopathy. Retina 2003; 23:771-6.

17. Nanda SK, Abrams GW. Relaxing retinotomies and retinectomies. Med Surg Retina 1994; 12:146-80.

18. Han DP, Lewis MT, Kuhn EM. Relaxing retinotomies and retinectomies: Surgical results and predictors of visual outcome. Arch Ophthalmol 1990; 108:694-7.

19. Federman JL, Eagle RC, Jr. Extensive peripheral retinectomy combined with posterior 360 degrees retinotomy for retinal reattachment in advanced proliferative vitreoretinopathy cases. Ophthalmology 1990; 97:1305-20.

20. Kolomeyer AM, Grigorian RA, Mostafavi D, Bhagat N, Zarbin MA. $360^{\circ}$ retinectomy for the treatment of complex retinal detachment. Retina 2011; 31:266-74.

21. Garnier S, Rahmi A, Grasswil C, Kodjikian L. Three hundred and sixty degree retinotomy for retinal detachments with severe proliferative vitreoretinopathy. Graefes Arch Clin Exp Ophthalmol 2013; 251:2081-5.

22. De Silva DJ, Kwan A, Bunce C, Bainbridge J. Predicting visual outcome following retinectomy for retinal detachment. $\mathrm{Br} \mathrm{J}$ Ophthalmol 2008; 92:954-8.

23. Zarbin MA, Michels RG, Green WR. Dissection of epiciliary tissue to treat chronic hypotony after surgery for retinal detachment with proliferative vitreoretinopathy. Retina 1991; 11:208-13

24. Sato T, Emi K, Bando H, Ikeda T. Retrospective comparison of 25-gauge vitrectomy for repair of proliferative vitreoretinopathy with or without anterior proliferation. Graefes Arch Clin Exp Ophthalmol 2014; 252:1895-902.<smiles>CC1C[Te]1C</smiles> 